\title{
Building brands through internal stakeholder engagement and co-creation
}

\begin{abstract}
Purpose - The purpose of the current paper is to better understand the voice of the internal stakeholder in a way that emphasizes the internal stakeholder as an active force and decisionmaker in brand co-creation, as part of the new emerging paradigm of internal branding. The main aim is to understand the active role of volunteers in internal branding, that is, in the cocreation of value. A subsidiary aim is to understand why some volunteers engage deeply and seriously in a nonprofit organization while other volunteers seem less connected?
\end{abstract}

Design/methodology/approach - A conceptual framework several motivators to volunteerled co-creation. A quantitative, co-variance-based SEM approach is used on survey data of a sample of 357 volunteers from 14 organizations in the Australian nonprofit sector.

Findings - The research findings contribute to the newly emerging internal branding literature focusing on the active co-creation role of internal stakeholders. The main drivers of volunteer co-creation are volunteer engagement, commitment, altruism, values-congruency and brand reputation. Different explanatory mechanisms/motivators apply to each type of volunteer-led co-creation. In a major initiative, the paper demonstrates linkages across the different types of co-creation, with a foundation/pivotal role for one particular type of co-creation, namely enhanced client-based solutions.

Research limitations/implications - The research is restricted to the public sector and further research is needed to test applicability to the private sector. Future studies could continue the initiative in the current study to explore the linkages across co-creation types.

Practical implications - Implications depend on which type of co-creation is targeted. Enhancing client-based solutions co-creation requires a very strong role for engaged volunteers. Innovation co-creation requires both engaged volunteers and a propensity to co- 
create by enhancing client-based solutions. Brand advocacy co-creation is driven by volunteer commitment, altruism and a propensity to co-create innovation.

Social implications - A non-profit context ensures major social implications.

Originality/value - The study operationalizes the Saleem and Iglesias (2016) new internal branding paradigm framework by demonstrating that brands are built organically by interacting and engaging with internal stakeholders (volunteers in this instance), which in turn, inter alia, motivates co-creation by such internal stakeholders.

Keywords Internal stakeholder co-creation, Motives for volunteer co-creation, Volunteer engagement, New internal branding paradigm 


\section{Building brands through internal stakeholder engagement and co-creation}

\section{Introduction}

A major premise of the internal branding literature is recognition of the importance of employees in delivering the brand to consumers and thus potentially boosting the brand equity of the firm (Gill-Simmen et al., 2018). In some cases, customers may consider the brand's employees as synonymous with the brand (Allison et al., 2016; Gill-Simmen et al., 2018). Internal branding activities proceed through stages: from internal brand communication, to training, and finally to brand delivery (M'zungu et al., 2016). The management goal is to use internal branding consistently, to deliver the firm brand to customers, enhancing the employee effort where possible. The internal branding literature focuses on the managerial levers that develop greater enhancement of employee effort, often through measures to increase employee attachment to the firm brand (Gill-Simmen et al., 2018). Three key sub-domains dominate the internal branding measures/triggers, namely transformational leadership, brand centred HRM and internal brand communication (Saleem and Iglesias, 2016).

Saleem and Iglesias (2016) identify a major limitation of the current internal branding literature to be its emphasis on a top down management approach and the neglect of the active role of internal stakeholders in co-creating the brand. A similar conclusion is drawn by Merrilees (2016a) in his review of internal branding. Traditionally, top management designs a brand and then uses internal branding to deliver the brand to consumers consistently. The employee has a relatively passive brand-building role in this respect. This neglect, or gap, provides the impetus for a new internal branding perspective or paradigm, one that recognizes employee and other internal stakeholders as active participants (co-creators) in the brand creation process (Merrilees, 2016a; Merz et al., 2009; Saleem and Iglesias, 2016). The Call for Papers highlights 
this new perspective, which offers the opportunity for a new sub-stream of internal branding research.

The current paper is positioned within this new paradigm as a contribution to the internal branding literature, supplementing the traditional stream that precedes it. The purpose of the current paper is to better understand the voice of the internal stakeholder in a way that emphasizes the internal stakeholder as an active force and decision-maker in brand co-creation. The paper helps to operationalize the Saleem and Iglesias (2016) conceptual framework of an internal stakeholder landscape. Two key concepts form the essence of the current paper's approach, namely internal stakeholder engagement and internal stakeholder co-creation. A further contribution is to introduce another major internal stakeholder entity, namely (unpaid) volunteers. Hitherto, employees have dominated attention in internal branding. By focusing on volunteers, the paper further recognizes the heterogeneity of internal branding stakeholders. Volunteers in Australian nonprofit services are the focus of the empirical study and represent about 20 percent of the total Australian workforce.

The paper has two specific aims. The first aim is to understand the role of volunteers in the cocreation of value in nonprofit organizations. The co-creation of value is an alternative to the prior paradigm of top-down value creation. The previous co-creation literature is customercentric and emphasizes the role of the consumer as a creator of value. Considerably less attention applies to the roles of other stakeholders, such as employees or volunteers, in value co-creation, a gap which this paper addresses.

The second aim, subsidiary to the first, is to examine the determinants of volunteer engagement in nonprofit organizations. Why do some volunteers engage deeply and seriously in a nonprofit 
organization while other volunteers seem less connected? Are there systematic reasons for such differences across volunteers? Many nonprofit organizations give attention to volunteer engagement, but there is a paucity of academic research to guide such endeavours. A quantitative research design is applied using an Australian sample. The paper begins with the literature review.

\section{Literature Review}

Several disparate literatures inform this study. Initially the traditional (top down) internal brand literature is briefly reviewed, followed by a synthesis of the emerging internal branding literature focusing on the active, co-creation role of internal stakeholders. Next, the literature review addresses other studies of volunteer co-creation and concludes with a review of volunteer engagement studies.

\section{Traditional internal brand literature}

In their systematic internal branding literature review, Saleem and Iglesias (2016) identify five major streams, namely brand ideologies (brand goals and values), brand leadership (particularly transformational leadership), brand-centred HRM (role of recruitment, training and rewarding), internal brand communication (both internal and external communication) and internal brand communities (shared platform for sharing brand related ideas). Similar facets are featured in the contemporary literature review by Merrilees (2016a). The early articles often emphasize the basic elements of internal communication and employee training (Punjaisri et al., 2009; Punjaisri and Wilson, 2011). Another group of articles emphasize the more sophisticated topic of the importance of transformational leadership in empowering employees (Burmann et al., 2009; Merrilees and Frazer, 2013; Morhart et al., 2009; Narissara et al., 2020; Wallace et al., 2013; Wieseke, et al., 2009). A further cluster of articles probes additional 
understanding by emphasizing culture and its role in enabling employees to live the brand (Baumgarth, 2010; Burmann et al., 2009; Gapp and Merrilees, 2006; Ind, 2003; 2004).

The traditional literature is well established and represents the point of departure for the current paper. In their internal branding literature reviews, both Salem and Iglesias (2016) and Merrilees (2016a) conclude that a major gap exists, namely an opportunity to understand the active role of internal stakeholders as a direct contributor to brand co-creation. The focus of the current paper is to address this gap, starting with a review of the scant literature that explicitly addresses the emerging paradigm subject of co-creation from an internal stakeholder perspective.

\section{Emerging internal branding literature focusing on the active co-creation role of internal}

\section{stakeholders}

More than a decade ago, Merz et al. (2009) argued that brands can be co-created through network relations and social interactions among the ecosystem of all (italics added) stakeholders. Several studies including Ind et al. (2012) and Iglesias et al. (2013) have emphasized the importance of employee stakeholders in co-creating brands. Yet it was not until 2016 that two literature reviews of internal branding identified a major weakness of internal branding being its confinement to a top-down approach and a failure to explicitly consider the active role of internal stakeholders in brand co-creation. Both Saleem and Iglesias (2016) and Merrilees (2016a) advocate the need for a new paradigm stream of internal branding research, to both supplement and counter the top-down, managerial domination of the traditional literature. 
Little progress appears to have been made to date, though a fragmented field of eleven empirical studies focusing on the explicit co-creation activities of internal stakeholders have been identified in the current paper. Four of the studies are qualitative (Dean et al., 2016; Jeanes, 2013; Schmeltz and Kjeldsen, 2019; Thelander and Sawe, 2015) and seven are quantitative (Cadwallader et al., 2010; Daily \& Bishop, 2003; de Jong \& Vermeulen, 2003; Devasagayam, 2010; Merrilees et al., 2017; Ordanini and Parasuraman; 2011; Zeithaml et al., 2009). All four qualitative studies interview multiple respondents in a single organization case format. All eleven studies focus on employees as the relevant internal stakeholder entity.

Dean et al. (2016) in a Mexican higher education study explore how employees co-create brand meaning through their brand experiences and social interactions with colleagues, customers and managers. The study emphasizes the initial socialization process when employees first join the university and how this learning develops over time. Jeanes (2013) is a case study of a UK SME retailer/manufacturer making their own cosmetic brands. The brand has a strong moralvalues character which motivates employees to engage with the brand and help co-create its brand meaning. Ironically, Jeanes (2013) argues that the strong brand largely created by employees ultimately and perhaps paradoxically controls the employees through its norms. Jeanes (2013) does not declare whether this is good or bad, but it may be inevitable in this brand type.

Schmeltz and Kjeldsen (2019) highlight the multiple voices of different employee stakeholder groups in the Danish National Gallery. Their findings show that the co-creation process can be thwarted by competing interests and conflict across the sub-groups, particularly between the curators and the marketing groups. A similar potential for conflict is shown by Thelander and Sawe (2015) in their study of a single (art) project conducted by a Swedish municipality. 
Tensions and different perspectives arise across the four different departments involved in the project, including an art versus marketing difference similar to that found in Schmeltz and Kjeldsen (2019). They disagree with Merz et al. (2009) that brand value is seamlessly cocreated within a stakeholder-based ecosystem. That is, Thelander and Sawe (2015) argue that in their case study there is no sign of co-creation as a dialogue-based process aimed at consensus. On the contrary, there was considerable disagreement, suggesting a need for greater internal support to enhance alignment. Absolute consensus cannot be attained, so they suggest a more feasible "comparable zone of meaning".

Five quantitative studies focus on just one facet of employee-led co-creation, namely service innovation. These studies show a connection between employee empowerment and service innovation (co-creation) by customer-facing staff (Daily and Bishop, 2003; de Jong and Vermeulen, 2003; Zeithaml et al., 2009). Additionally, Ordanini and Parasuraman (2011) show that the strongest driver of service innovation (co-creation) comes from frontline employee participation. Further, Cadwallader et al. (2010) demonstrate a role for motivation theory to explain why customer-facing employees participate in service innovation implementation.

Of the two remaining quantitative studies focusing explicitly on internal stakeholder driven cocreation, Merrilees et al. (2017) is the more general and directly examines co-creation determinants. They use an Australian study of nonprofit organizations and demonstrate that employee engagement, along with values-congreuncy, employee empowerment and employee commitment, can contribute to employee-led co-creation. Three employee stakeholder groups, namely customer-facing employees, backstage employees and supervisors, all co-create. The other quantitative study by Devasagayam (2010) is relevant in that it seems to be one of the few explicit studies of internal brand communities. They show that American internal brand 
communities augment managerial internal branding in building stakeholder brand value. There are some limitations in that the sampling frame is vague, including the ill-defined nature of the panel respondents and the construct items are not shown (but seem to be peculiarly based on a prior fan/customer study rather than an employee study). In principle, at least, the Devasagayan (2010) study suggests the possibility of measuring how well (informal) internal stakeholder networks communicate and share brand knowledge.

In summary, the internal branding literature stream that focuses on the active role of internal stakeholders as co-creators is now grouped as a distinct sub-stream. The eleven empirical articles reported here fit into the suggested schema proposed by Iglesias and Saleem (2016). Broadly, the Iglesias and Saleem (2016) schema seeks a better understanding of the entire internal stakeholder landscape, including multiple employee (and other) groups, with an emphasis on the active participation of these internal stakeholders in the brand co-creation process. This stream of internal branding takes an organic view of the brand, where the corporate brand is not simply handed down, but rather is co-created within a multiple stakeholder network (Iglesias et al., 2013). Notwithstanding, this new sub-stream of internal branding research is embryonic, with scope for further research. The eleven articles stress the nature of internal stakeholder co-creation, but generally fail to explore the motivation for internal stakeholders to participate in co-creation. An exception is Merrilees et al. (2017) who demonstrate that factors like empowerment and engagement do motivate employee-led cocreation. Firstly, the current paper will draw on and extend Merrilees et al (2017) in attempting to understand why co-creation occurs. Secondly, the current paper will also extend the scope of internal stakeholders from employees to another major group, volunteers.

\section{Volunteer service co-creation}


Potentially any task that a volunteer performs is tantamount to co-creation because their work is unpaid. The current study adopts a narrower definition, namely that volunteer co-creation is behaviour that exceeds normal transactional expectations, something that goes beyond normal duties. Volunteers, like paid staff, make co-creation contributions. Nonetheless, in a review of 60 volunteer studies by Alfes et al. (2017) examining organizational outcomes from volunteers, no mention is made of volunteers contributing through co-creation. The role of volunteers in service co-creation is present in the literature, though often in obscure or fragmentary ways. Primarily, the case of volunteers recruiting other volunteers through word-of-mouth is the most common treatment. The nonprofit literature recognizes such a role (Baxter-Tomkins and Wallace, 2009; Low et al., 2007; Ockenden and Hutin, 2008). However, the magnitude of this role is rarely quantified, despite its probable importance in areas like emergency services (Baxter-Tomkins and Wallace, 2009). Brand advocacy co-creation by volunteers seems important, but few studies estimate the magnitude of the activity.

A project-based study by Miller and Merrilees (2013) gives an example of a disability-based community organization utilizing multiple stakeholders, including managers, employees, clients, carers and the community to collaborate (co-create) in organizational rebranding. Jaakkola and Alexander (2014) study volunteer co-creation behaviour in ScotRail. Their qualitative study derives four types of co-creation behaviour: augmenting behaviour; codeveloping behaviour; influencing behaviour; and mobilizing behaviour.

\section{Volunteer brand engagement}

The current paper couples the role of engagement with co-creation, building on Merrilees et al. (2017) in the internal branding stakeholder literature and also on the customer-led co-creation literature (France et al., 2018). Engagement plays a role as a determinant/motivator of co- 
creation. The current study uses the definition of volunteer brand-engagement as a psychological disposition of the volunteer to engage with the organizational brand (Bowden, 2009; Brodie et al., 2011; Hollebeek 2011). Broadly, a discursive study by Thomas (2016) suggests that volunteer engagement can be enhanced by two antecedents, namely when volunteer motivations are accommodated and when organizational support is provided.

Several recent empirical studies elaborate on the two types of engagement antecedents that Thomas (2016) proffers. A systematic review of a range of volunteer issues by Alfes et al. (2017) suggests that the degree of meaningfulness of tasks may match the volunteer's intrinsic motivations and encourage volunteer engagement. In a major study, Shantz et al. (2014) propose and test a relationship between the values motive and engagement with volunteer work. Their values motive includes the expression of values related to altruistic or humanitarian beliefs. They argue that volunteers who are motivated by altruistic or humanitarian values may engage more in volunteer activities because the activities enable them to express their preferred self, compared to volunteers who are less motivated by values. Using a survey of volunteers with an international aid and development agency in the UK, Shantz et al. (2014) estimate a model that includes a path from values to engagement.

Harp et al. (2017) include a similar concept to values, which they term community service selfefficacy, as a moderating influence on the organizational support to the engagement path. Their results show a small but significant role for community service self-efficacy. Harp et al. (2017) demonstrates the role of organizational support in facilitating volunteer engagement. Alfes, et al. (2016), similarly demonstrate engagement as a function of two organizational support variables. 
A final empirical study of volunteer engagement adds a new dimension. Curran et al. (2016) examine the role of brand heritage in having a positive bearing on the level of engagement among U.K. Scouts volunteers. A possible link between brand heritage and volunteer engagement draws on the connection between brand orientation and nonprofit sector organization performance (Napoli, 2006) and a positive relationship between brand orientation and staff attachment to a nonprofit organization's brand (Liu et al., 2015). Curran et al. (2016) demonstrate a sizeable and significant path between brand heritage and volunteer engagement in the U.K. Scouting sector.

The current study proposes that volunteer's altruistic values on the one hand and congruency of values between the volunteer and the nonprofit organization on the other hand should be treated as two different phenomena affecting volunteer engagement. The values of an organization are much broader than altruistic values, so there is a sound case to separate the two concepts when studying volunteer engagement.

\section{INSERT FIGURE 1 HERE}

\section{Conceptual model}

The two core components of the volunteer-led co-creation model are volunteer co-creation and volunteer engagement (see Figure 1). Engagement is conceived of as a psychological predisposition and is postulated to be a major determinant/motivator of co-creation. The nexus between engagement and co-creation builds on Merrilees et al. (2017) from the employmentled co-creation field and France et al. $(2015 ; 2018)$ from the consumer-led co-creation field cocreation domain. Further support for an engagement to co-creation path comes from empirical 
studies in brand community (Algesheimer et al., 2005) and in social media (De Vries and Carlson, 2014).

For the first part of this model it is necessary to specify and justify (through the literature) each path explaining volunteer engagement. Four antecedents of volunteer engagement are proposed: volunteer empowerment; values-congreuncy between the volunteer and the nonprofit; brand reputation of the nonprofit; and the volunteer's altruistic motives to remain in the nonprofit organization.

The first of the four paths to volunteer engagement stems from volunteer empowerment. Conceptually, the argument is that if volunteers are given the freedom and authority to make decisions, then they will be emotionally motivated to engage, that is, putting in more effort, passion and attention to their work. Empirically, the direction of the path is supported in volunteer engagement studies (Alfes et al 2016; Harp et al., 2017). The same path is supported in many employee-based empirical studies (Cattermole et al., 2013; Fernandez and Moldogaziev, 2013; Jose and Mampilly, 2014; Lee et al., 2014; Rich et al., 2010).

The second path is from values-congruency to volunteer engagement. Conceptually, if volunteers share similar values to the nonprofit organization, then this close fit will encourage them to engage more. Empirically, values-congreuncy has received some consideration in the volunteer engagement studies (Alfes, et al. 2017) and also employee-based engagement studies; Merrilees et al., (2017). Similarly, the values-congruency to engagement path is supported in consumer brand studies (De Vries and Carlson, 2014; France et al., 2016). 
The third path is from volunteer altruistic motivations to volunteer engagement. Conceptually, altruistic values have been central throughout the nonprofit/volunteer literature (Thomas, 2016) and are considered germane to most volunteer decisions interacting with the organization, especially willingness of the volunteer to engage or stay with the organization (Merrilees et al. 2020). Empirical studies support the volunteer altruistic motivations to volunteer engagement path (Alfes et al., 2016; Harp et al., 2017; Shantz et al., 2014).

The fourth and final postulated engagement path is from brand reputation to volunteer engagement. Conceptually, it might be expected that if volunteers have a strong regard for the brand reputation of the nonprofit, then this will pre-dispose them to engaging with the nonprofit. Empirically, there is limited research to date in the volunteer literature, save for the qualitative study by Curran, et al. (2016). Empirically, there is some support for a brand reputation to engagement path in the consumer context, using brand strength as a possible counterpart substitute to brand reputation (De Vries and Carlson, 2014).

In summary, the above four engagement paths are supported conceptually and empirically in different literatures and represent a promising explanation of volunteer engagement. Before progressing to the co-creation paths, the current conceptual model proposes three different types of volunteer co-creation: volunteer brand advocacy co-creation; volunteer service innovation co-creation; and volunteer proactive client helping co-creation. The first co-creation type refers to the role of the volunteer in actively recruiting either new clients or new volunteers. The second co-creation type refers to the active role of the volunteer in contributing to service innovation. The third co-creation type refers to the extra, beyond normal contribution of the volunteer to supporting clients. This taxonomic treatment of co-creation is supported in the qualitative study of volunteer-led co-creation by Jaakkola and Alexander (2014), in the 
employee-led co-creation by Merrilees et al. (2017) and in the consumer-led co-creation study by Yi and Gong (2013). Each of the three co-creation types is a different facet of co-creation with probably different motivational drivers and thus warranting separate investigation.

Engagement is one of the two focal components of the model, supported by Algesheimer et al. (2005), De Vries and Carlson (2014), France et al. (2018) and Merrilees et al. (2017). Paths (see Figure 1) run from volunteer engagement to two of the three facets of co-creation, namely volunteer proactive client helping co-creation and volunteer service innovation co-creation. Engagement is very much about the here and now of being passionate and immersed in the workplace and thus likely to have its greatest influence in the day to day operational opportunity of proactive helping client co-creation. To a lesser extent, engagement is also likely to influence volunteer innovation co-creation, but less frequently than the proactive helping client co-creation. On the other hand, brand advocacy is an off-site activity, somewhat detached from the cut and thrust of being immersed in daily operations, with limited opportunities to enact and thus unlikely to be influenced by a state of engagement.

Further, empowerment is likely to directly influence volunteer innovation co-creation. The role of empowerment in stimulating engagement, defined as a psychological disposition, has already been argued. However, co-creation is an active behavioural act requiring more than just a willingness to act (which engagement picks up). Empowerment also represents a capacity to freely act and thus warrants inclusion as a separate determinant of co-creation. Empirically, support for an employee-based empowerment to service innovation path comes from several studies, including Daily and Bishop (2003), de Jong and Vermeulen (2003), Merrilees et al. (2017) and Zeithaml et al (2009). 
Values-congruency is a possible determinant of proactive helping client co-creation. At the frontline, volunteers are more likely to be motivated to go the extra mile with client solutions if there is alignment of their values with the brand. Support for this path comes from Hakanen and Jaakkola (2012). They examine critical factors affecting the effective co-creation of customer-focused solutions within a business network and identify "fit" (between the supplier and the client) as such a factor. Values-congruency is a "fit" factor as postulated here. Merrilees et al. (2017) also supports a link between values-congruency and proactive helping client cocreation. Brand reputation is another possible determinant of proactive helping client cocreation. If volunteers perceive high brand reputation, then they might work harder (cocreating) at client-focused solutions. Some support for this link comes from Dwivedi et al. (2015).

Another major element to the co-creation story is the addition of a path from commitment to brand advocacy co-creation. The literature overwhelmingly emphasizes staff (volunteer) commitment as the driving force explaining brand advocacy. In their employment-led cocreation study Merrilees et al. (2017) supports such a path. Similarly, several studies have identified a link between commitment and word of mouth advocacy, closely related to brand advocacy co-creation (Burmann, et al., 2009; Piehler et al., 2018). Further support for the commitment to brand advocacy co-creation comes from the consumer-led co-creation domain (Čater and Čater, 2010; Olaru et al, 2008). A possible explanation for the narrower (single facet) influence of commitment, might be that word of mouth, or client and volunteer recruitment by volunteers, requires the least effort of the three co-creation types. Thus, volunteers who are committed, but not necessarily strongly engaged or empowered, might be inclined to recommend the nonprofit organization, but may be unwilling to expend extra effort to provide ideas for service innovation or give clients special help. 
Volunteer altruistic motivations is another potential determinant that might apply to brand advocacy. In context, brand advocacy is about helping clients directly access the services of the brand or indirectly helping by expanding the volunteer workforce. Altruism is about helping clients and the cause, so more altruistic volunteers are more likely to be brand advocates. Our proposed link here is conceptual, as there is no prior testing of such a relationship.

To further build the model, antecedents are needed for commitment. Two antecedents are applicable, values-congruency and empowerment, both positively building volunteer commitment (Figure 1). Support for these two antecedents includes Merrilees et al. (2017) and Riketta (2005).

A final consideration of the model is to explore whether there are linkages between the three co-creation variables. Proactive helping client (that is, enhanced client-based solutions) cocreation seems a useful starting place because such behaviours are more prevalent (of the three co-creation types) in the day to day operations of the workplace. As several authors (Dean et al., 2016; Merrilees, 2016b; Minkiewicz et al., 2014; Shamim et al., 2016) argue, the lived experiences and interactions across stakeholders are the catalyst to co-creation processes. Enhanced client-based solutions are a possible foundation of brand experiences that build brand learning that can be applied to a second co-creation type, volunteer innovation co-creation. That is, by delivering enhanced client-based solutions, some volunteers may be able to generalize from their individual co-creation encounters to giving the organization suggestions for them to undertake organization-wide service innovation improvements. Volunteers learn from their own co-creation activities and pass on the learning, so eventually other volunteers (and staff) can also learn and thus escalate the brand innovation benefits. Therefore we expect a path from proactive helping client co-creation to innovation co-creation. 
Another possible linkage between co-creation types is from volunteer innovation co-creation to volunteer brand advocacy co-creation. The argument here is that volunteers who actively contribute to service innovation are likely to build up an even stronger appreciation of the brand they work for because they know it has been strengthened by the innovation. Such increased confidence is likely to increase the propensity of such volunteers to advocate for the brand, generating a link from volunteer innovation co-creation to brand advocacy co-creation. The Figure 1 model is now complete.

\section{Method}

The study uses a quantitative approach collecting data from volunteers in nonprofit organizations because the objective is to quantify the various paths in the Figure 1 conceptual model. A quantitative method is the only way of delineating the relative importance of different motivators for volunteers to co-create the brand, and contrasts with much of the existing literature in the new sub-stream of internal branding being qualitative.

Criteria for selecting respondents follow a four-step process. Firstly, only nonprofit service organizations are included, as a means of giving a specific service industry focus to the study. Secondly, the population frame was further restricted to organizations that were publically identified by winning or being nominated for various awards, such as for rebranding. Thirdly, the researchers approached the identified nonprofit organizations to request their participation in the study. Specifically, the researchers initially contacted senior managers and explained the purpose of the proposed study and the potential benefits to the organization from participation. In some cases, the researchers agreed to provide a customized report. Fourthly, if the 
organizations agreed to participate in the study, their volunteers were formally invited to participate in the project. The researchers provided assurance to the volunteers about the confidentiality of their responses.

All participating organizations were nonprofit in character. By design, the scope of their activities varies widely. Organizations, which participated in the study, range from disability services to community arts and education.

The structured survey covered the following variables: volunteer brand engagement; volunteer empowerment; volunteer commitment; values-congreuncy and three types of volunteer-led cocreation. Demographic variables were also collected. Where possible, scales are from the literature. For example, the volunteer engagement scale is slightly adapted from Rich et al. (2010) and Merrilees et al. (2017). The three volunteer-led co-creation scales are adapted from Yi and Gong (2013) and Merrilees et al. (2017). The values-congruency scale was derived from Hoffman et al. (2011). The commitment scale was derived from Allen and Meyer (1990). For the altruistic motivations scale was derived from Shantz et al. (2014) and Merrilees et al. (2020). Avolio et al. (2004) was the source of the empowerment scale. The brand reputation scale was adapted from Veloutsou and Moutinho (2009). The structured survey uses 5-point Likert scales [anchored at 1 for strongly agree and 5 for strongly disagree].

The volunteer respondents were from fourteen nonprofit organizations. The participants responded using the self-administered structured survey, which was available either online or in hard copy, contingent to the organization. Lin and Van Ryzin (2012) argue that there is little difference in the characteristics of respondents using either response mode. Four organizations used the print surveys together with an online survey with comparable format; two 
organizations used print only; and eight used online only. After data cleaning there were 357 usable responses.

\section{Data analysis method}

Given the objective to quantify the various factors in a complex (multi-tiered) model like Figure 1, structural model estimation (Structural Equation Modelling) is suitable. Further, given the emphasis of understanding and delineating the relative importance of different motivators for volunteers to co-create to the brand, a co-variance-based SEM is required rather than a variance-based SEM. The study uses AMOS software (Version 25) for the data analysis.

More specifically, the current study uses the parcelling method (that is, a partial disaggregated method of analysis), following Dabholkar et al. (1996), and others, including Merrilees and Miller (2019). This method is executed by creating two composite variables for each construct, by randomly selecting indicator items and then averaging them. The advantages of such an approach include the reduction of measurement error, lessening the chances of spurious correlations among scale items, and achieving more stable structural co-efficient estimates (Little et al., 2002).

\section{INSERT TABLE 1 ABOUT HERE}

\section{Results}

\section{Preliminary Results}

The preliminary results indicate that a reasonable cross-section representation is achieved by the sampling. The median duration of volunteering is 2.1 years, with 31 percent of the sample 
serving five or more years and 13 percent ten or more years. About 29 percent of the sample has given about one year of service. The numbers by age group are: 61 [18-24 yrs.], 59 [25-34 yrs.], 41 [35-44 yrs.], 73 [45-54 yrs.], 74 [55-64 yrs.], 33 [65-69 yrs.], and 16 [70+ yrs.]. Women predominate at 77 percent of the sample, which reflects in part a female-centric population in volunteering.

Several tests demonstrate reliability and validity of the scales. Table 1 shows measures of reliability for each scale, with all scales reliable with Cronbach Alphas greater than the threshold of 0.70 (Nunnally and Bernstein, 1994). Table 1 also demonstrates convergent validity with high factor loadings for the items in each scale. AVE greater than 0.50 also indicate convergent validity. Discriminant validity is demonstrated by two methods. Firstly, using Fornell and Larcker (1981), all scales discriminate against each other, with each pair of constructs having AVE greater than the square of the correlation between the two constructs (see Table 2). Secondly, the Henseler et al. (2015) test measures the Heterotrait-monotrait ratio of correlation (HTMT). The HTMT ratios range from 0.28 to 0.78 , with the highest ratio appropriately less than one, again indicating discriminant validity.

\section{Insert Table 2 about here}

\section{Confirmatory Factor Analysis}

Before conducting estimation of the structural equation model, it is necessary to conduct Confirmatory Factor Analysis. That is, each construct is specified to covariate with all other constructs (thus an absence of any dependent variables). The model fit for CFA is very satisfactory, as follows. The Chi-square $\left(\chi^{2}\right)$ is 156.3 with $\mathrm{df}=99$. The baseline fit indices include CFI=0.99 and TLI=0.98, both above the 0.90 benchmark (Hair et al. 2006). 
RMSEA $=0.040$ is appropriately low and below the 0.08 benchmark (Hair et al. 2006). It is now appropriate to proceed to estimation of the structural equation model.

\section{Structural Model Results}

The SEM structural model fit indices are satisfactory. The Chi-square $\left(\chi^{2}\right)$ is 177.8 with $\mathrm{df}=$ 114 and a normed fit $\chi^{2} / \mathrm{df}=1.56$, appropriately less than three. CFI $=0.99$ and TLI=0.98, both above the 0.90 benchmark (Hair et al. 2006) for a good fit of the model with the data $(n=357)$. RMSEA $=0.040$ with a 90 percent confidence range of 0.028 to 0.051 , with the entire range appropriately below the 0.08 threshold and indicating a low level of misfit of the model with the data (Hair et al. 2006). The Bollen-Stine $p=0.055$, which is appropriately insignificant (at the 0.05 level), a further indication that the model fits the data. The model strongly explains the variance in each type of co-creation, highest at 61 percent for brand advocacy co-creation, followed by 54 percent for enhancing client-based co-creation and 49 percent of the variance in innovation co-creation.

\section{INSERT TABLE 3 HERE}

Table 3 also shows the three structural sub-models for the three different forms of volunteer co-creation, namely co-creating with clients; co-creating with the organization in terms of giving ideas for service innovation; and volunteers co-creating through brand advocacy. As expected, volunteer engagement plays an important role, especially strong for the proactively helping client type of co-creation. The link between volunteer engagement and volunteer innovation co-creation is also strong at the 0.01 level.

Commitment is the dominant explanatory variable in stimulating brand advocacy co-creation. Another influence, also at the 0.01 level, on brand advocacy comes from volunteers' altruistic motivation Engagement is supported by two other variables in influencing the proactively 
helping client type of co-creation, both at the 0.05 level. Values-congruency has a slightly greater influence compared to brand reputation.

Links between the three co-creation types are important. The initial link goes from enhanced client-based solutions to innovation co-creation, with a very large path coefficient of 0.48 , significant at the 0.01 level. A subsequent link goes from innovation co-creation to brand advocacy co-creation, with a large path coefficient of 0.36 , significant at the 0.01 level. Thus, both links between co-creation types contribute an important part of the volunteer co-creation story.

Table 3 also reports the structural model estimates in terms of explaining volunteer engagement. The estimates for the engagement model indicate that altruistic motivation and empowerment are both very strong determinants of engagement, with solid support from two other factors: values-congruency and brand reputation. The first two variables (empowerment and altruistic motivation) are statistically significant at the 0.01 level, and the next two variables (brand reputation and values-congruency) significant at the 0.05 level.

Finally, paths to commitment is included, not as an end in itself, but because commitment is an antecedent to brand advocacy co-creation. Two determinants emerge for commitment. Valuescongreuncy is the dominant explanation, with a path coefficient of 0.66. Additionally, empowerment also increases volunteer commitment, at the 0.01 level.

\section{Discussion}


The rationale of the current paper has been to better understand the voice of the volunteer internal stakeholder in a way that emphasizes the internal stakeholder as an active force and decision-maker in internal branding and thus brand co-creation. The conceptual and empirical results demonstrate a viable model that is able to successfully demonstrate, explain and understand the active participation of volunteers in co-creation activities. Volunteers are the focal decision-maker, driven by both innate and external motives, rather than passive parties to organizational direction. This finding contributes to the new paradigm of internal branding.

Rather than a traditional top-down perspective of internal branding where traditional management tools such as communication and training drive a management-determined brand, the results support the organic view where the brand is co-created within a multiple stakeholder network (Iglesias et al. 2013; Saleem and Iglesias, 2006).

Previously, the new active internal stakeholder paradigm of internal branding had some but limited empirical backing. A major contribution of the current study has been to operationalize the new framework by conceptualizing and testing a model explaining volunteer (as an internal stakeholder) motivation to co-create. The study demonstrates the need for managers to interact with all internal stakeholders, including volunteers and employees, to get these internal stakeholders engaged with the brand (thus an interactive process) and in turn to motivate the same stakeholders to participate with and co-create the brand.

To achieve operational execution of the new internal branding perspective, the model is designed to, and does successfully, explain the actual co-creation decisions of volunteers. A major factor in understanding why volunteers participate in co-creation, is volunteer engagement. If volunteers are strongly engaged, then they are very likely to co-create. This 
finding is consistent with the employee-led co-creation study of Merrilees et al. (2017). A similar nexus between engagement and co-creation is shown in the consumer-led co-creation field (France et al. 2005; 2018), in the brand community co-creation field (Algesheimer et al., 2005) and in the social media co-creation field (De Vries and Carlson, 2014). A volunteer study by Shantz et al. (2014) also demonstrates a link between volunteer engagement and volunteer co-creation, but the latter is defined too broadly as simply time dedicated to volunteering. Such a broad definition would be unable to explain why two volunteers spending similar hours of volunteering could differ markedly in terms of the three facets of co-creation used in the current study.

Probing the results further, the three types of volunteer co-creation are explained by three different sets or different weightings of motivators. Unlike the other two types of volunteer cocreation, volunteer engagement did not contribute to brand advocacy co-creation, a role assumed primarily by volunteer commitment. The last finding does not seem to be explicit in any previous volunteer research, though it is consistent with numerous studies in the traditional internal branding literature (Burmann, et al., 2009; Piehler et al., 2018). For volunteers, commitment of volunteers is almost sufficient to get them to participate in brand advocacy cocreation. Compared to the other two forms of co-creation, it is not critically important to get the volunteers engaged; that is, the bar to get brand advocacy co-creation is lower than for the other two forms of co-creation. A second determinant of volunteer brand advocacy is the propensity of the volunteer to participate in another type of co-creation, namely innovation cocreation. This will be discussed below. A third determinant of volunteer brand advocacy cocreation is the altruistic motivation of the volunteer. Altruism, by nature, is directed at compassionately helping clients deal with life challenges. One of the facets of brand advocacy 
co-creation is the active recruitment of new clients by volunteers; thus, volunteers with a stronger altruism drive are more likely to actively recruit new clients.

Proactively (extra role) helping client type of co-creation has its own particular set of motivating drivers. Engagement of volunteers is especially important to get volunteer participation. Providing extra brand value to client-facing roles requires a passionate and dedicated volunteer. Further, participation is facilitated by volunteers' values-congreuncy. A close fit between the volunteer and the brand increases the propensity to contribute enhanced client-based solutions, as the staff-client literature suggests (Hakanen and Jaakkola, 2012). A third determinant of the proactively helping client type of co-creation is brand reputation. Volunteers are more likely to invest in going beyond normal expectations in their client interactions, if their cause has a strong brand reputation (c.f. Dwivedi et al., 2016 regarding consumer co-creation).

The third and final co-creation type in this study, service innovation, is perhaps the most complex in terms of requiring extra knowledge and investment effort, and certainly has been the most difficult to explain. As shown, volunteer engagement emerges as a strong driver of volunteer service innovation. That is, it requires a lot of passion and determination to get the volunteer to participate in this type of co-creation. However, the greatest determinant of innovation co-creation is another type of co-creation, namely proactively helping clients type of co-creation. This aspect will be discussed below. A third determinant of innovation is volunteer empowerment, though this is a very small and marginal influence.

A major feature of the results is demonstration of linkages between types of co-creation, apparently the first study to do so. Enhancing client-based solutions (co-creation) are posited 
as the foundation building bricks of brand experiences that build brand learning, that in turn can be leveraged to a second co-creation type, volunteer innovation co-creation. That is, by cocreating through delivering enhanced client-based solutions, some volunteers are able to generalize from their individual co-creation encounters to give feedback and new ideas to the organization, which can be shaped ready for organization-wide service innovation improvements. Volunteers learn from their own co-creation activities and pass on the learning so eventually other volunteers (and perhaps staff) can also learn, thereby multiplying the brand innovation benefits. It is important for organizations to appreciate the foundation role of the enhanced client-based solutions type of co-creation.

Another demonstrated linkage between co-creation types is from volunteer innovation cocreation to volunteer brand advocacy co-creation. Arguably, volunteers who actively contribute to service innovation are likely to build up an even stronger appreciation of the brand they work for because they know it has been strengthened by the innovation. Such increased confidence increases the propensity of the same volunteers to advocate for the brand.

Volunteer engagement is an important part of the internal branding process. Having strongly engaged volunteers is critical to motivate volunteers to actively participate in the various facets of co-creation to complete the internal branding process. The literature review demonstrates a patchy understanding of volunteer engagement. In contrast, the current model results provide a comprehensive understanding of the drivers of volunteer engagement. In brief, the current paper provides a four-prong approach: altruistic motivation; values-congreuncy; empowerment and brand reputation.

Finding four statistically significant, roughly equal, determinants of volunteer engagement provides a robust suite of relevant engagement drivers. Examining the mix of these drivers 
gives further insight into the mindset of a major internal stakeholder. Only one driver, brand reputation, might be considered essentially a management-driven factor, though even here it is the perception of the volunteer that counts. One driver, altruistic motivation, is an innate (to the volunteer) motivator of engagement. The other two engagement determinants, namely values-congruency and empowerment, are a combination of management and innate forces, but emphasize the innate perspective of the volunteer.

Consistent with the current paper emphasis is the work by Tossavainen (2017) who argues that service development is stronger through engaging multiple stakeholders in joint activities. Parallel to the "customer" in Edvardsson et al. (2011), perhaps the "volunteer" as well as the "employee" could be conceived as a resource integrator framed in a system of social ties, norms and values.

Derived from consumer brand engagement studies (Fernandes and Moreira, 2019), engagement is closely linked to emotional relationships. Other consumer engagement studies (Bolten, 2011; Merrilees, 2016b) further suggest the need to understand the total set of interactive brand experiences positively influencing consumer engagement. While the current study makes some progress towards understanding the relevant volunteer interactive experiences (in an internal branding context) influencing volunteer engagement, more research is needed.

\section{Limitations and future research}

The results for any early stage research always require additional studies to confirm the generalizability of the findings. The literature review indicated few quantitative studies to date in the literature of the new paradigm of internal branding, that examining the active participation of internal stakeholders in brand co-creation. Previous studies and the current 
research have usually been confined to the public sector, so it would be interesting to see evidence of internal stakeholder controlled internal branding in the private sector. Presumably purpose-driven private industry organizations (see Jeanes 2013 as an initial possibility) could reveal passionately engaged staff who activate their own internal branding process?

Another future research possibility would be to further develop the whole conceptual internal branding landscape, integrating the various multiple stakeholders, and including tighter specification of the internal network. Studies like Schmidt and Baumgarth (2018) can guide deeper understanding of linkages in the internal branding network. Consumer brand community research, including the importance of socialization, can be leveraged to the internal brand community domain. Socialization is likely to be even more important for internal brand communities. A number of the reviewed qualitative employee-led co-creation studies already signal a role for socialization (Dean et al., 2016; Jeanes, 2013). Relationship management in a co-creation context could also be incorporated into developing the enlarged internal branding landscape (Veloutsou and Moutinho, 2009). Indeed, there has been little follow-up to the Palmer (1996) article integrating branding and relationships, which would be interesting and especially relevant to explore in the internal branding landscape context. Future studies could continue the initiative in the current study to explore the linkages across co-creation types.

\section{Practical implications}

The paper provides a soundly based internal branding framework based on active internal stakeholder participation that can guide the volunteer programs of nonprofit organizations. Nonprofit organizations seeking more co-creation contributions from their volunteers, can now undertake more informed actions. Volunteer engagement is shown to be a central lever for any 
future strategy. Other potential levers could be based on volunteer commitment, volunteer altruistic motivations, volunteer values-congruency and brand reputation.

Discussion of the results suggests that future management co-creation programs would benefit from finer level delineation of exactly what type of co-creation was being targeted. If the most complex variant of co-creation, service innovation, was the target, for example, then special attention should be paid to volunteer engagement and the propensity of volunteers to participate in another type of co-creation, namely proactively helping client co-creation. This in turn suggests the opportunity to understand the whole system of co-creation, with well-defined linkages across the different types of co-creation. Another idea might be to establish a digital platform enabling volunteers to more easily and accurately contribute ideas and suggestions for service delivery and process improvements. A further possibility is using internal ambassador programs to boost co-creation, along the lines indicated by Schmidt and Baumgarth (2018) in their analysis of using brand ambassador programs to strengthen internal brand equity. Turning to another co-creation type, namely enhancing client-based solutions, the results indicate a very strong role for engaged volunteers.

The new internal branding paradigm can also be applied to volunteer engagement. Four drivers of volunteer engagement, empowerment, altruistic motivation; values-congreuncy; empowerment and brand reputation are identified as potential targets of future strategy. Empowering the volunteer in some decision-making is a major opportunity and particularly feasible for any transformational leaders, who excel in empowerment. Appealing to innate altruistic motivations is another possibility in any strategy, though recruiting the right volunteers with the right values and motivations in the first place would be an appropriate policy. 
In conclusion, the paper has synthesized the fledging literature of the emerging internal branding sub-stream focusing on the active participation to of internal stakeholder to internal branding. Additionally, the results of the current paper recast a particular internal stakeholder group, volunteers, as a major, active participant in brand building efforts. A special emphasis of the current paper is to operationalize the Saleem and Iglesias (2016) framework by highlighting the interactive engagement of internal stakeholders with the brand, which in turn drives their co-creation efforts with the brand.

\section{Disclosure statement}

The authors report no potential conflict of interest.

\section{Acknowledgements}

We are especially thankful for the meticulous and insightful feedback and guidance from the three reviewers as well as the Guest Editors. The contributions have turned the traditional reviewing process into an exemplary illustration of a journey concomitant with the new paradigm of total internal stakeholder participation and co-creation. 


\section{REFERENCES}

Alfes, K., Antunes, B. and Shantz, A. (2017), "The management of volunteers - what can human resources do? A review and research agenda", International Journal of Human Resource Management, Vol. 28 No. 1, pp. 62-97.

Alfes, K., Shantz, A. and Bailey, C. (2016), "Enhancing volunteer engagement to achieve desirable outcomes: What can non-profit employers do?", Voluntas, Vol. 27, No. 2, pp. $595-617$.

Algesheimer, R., Dholakia, U. and Hermann, A. (2005), "The social influence of brand community: Evidence for European car clubs”, Journal of Marketing, Vol. 69 (July), pp. 19-34.

Allen, N. and Meyer, J. (1990), “The measurement and antecedents of affective, continuance, and normative commitment to the organization", Journal of Occupational Psychology, Vol. 63 No. 1, pp. 1-18.

Allison, L., Flaherty, K., Jung, E., and Washburn, I. (2016), “Salesperson brand attachment: A job demands-resources theory perspective", Journal of Personal Selling \& Sales Management, Vol. 36 No. 1, pp. 3-18.

Avolio, B., Zhu, W., Koh, W. and Bhatia, P. (2004), “Transformational leadership and organizational commitment: Mediating role of psychological empowerment and moderating role of structural distance”, Journal of Organizational Behavior, Vol. 25 No. 8, pp. 951-968.

Baxter-Tomkins, T., and Wallace, M. (2009), "Recruitment and retention of volunteers in Emergency Services", Australian Journal on Volunteering, Vol. 14 No. 5, pp. 39-49.

Bolten, R. (2011), "Comment; customer engagement: opportunities and challenges for organizations", Journal of Service Research, Vol. 14 No. 3, pp. 272-274.

Bowden, J. (2009), “The process of customer engagement: A conceptual framework”, Journal of Marketing Theory \& Practice, Vol. 17 No. 1, pp. 63-74. 
Brodie, R., Hollebeek, L., Jurić, B., \& Ilić, A. (2011), “Customer engagement: Conceptual domain, fundamental propositions, and implications for research", Journal of Service Research, Vol.14 No. 3, pp. 252-271.

Burmann, C., Zeplin, S. and Riley, N. (2009), "Key determinants of internal brand management success. An exploratory empirical analysis”, Journal of Brand Management, Vol. 16 No. 4, pp. 264-284.

Cadwallader, S., Jarvis, C., Bitner, M. and Ostrom, A. (2010), "Frontline employee motivation to participate in service innovation implementation", Journal of Academy of Marketing Science, Vol. 38 No. 2, pp. 219-239.

Čater, T. and Čater, B. (2010), "Product and relationship quality influence on customer commitment and loyalty in B2B manufacturing relationships", Industrial Marketing Management, Vol. 39, pp. 1321-1333.

Cattermole, G., Johnson, J. and Roberts, K. (2013), "Employee engagement welcomes the dawn of an empowerment culture”, Strategic HR Review, Vol. 12 no. 5, pp. 250-254.

Curran, R., Taheri, B., MacIntosh, R. and O'Gorman, K. (2016), “Nonprofit brand heritage: Its ability to influence volunteer retention, engagement, and satisfaction", Nonprofit and Voluntary Sector Quarterly, Vol. 45 No.6, pp. 1234-1257.

Dabholkar, P., Thorpe, D. and Rentz, J. (1996), “A measure of service quality for retail stores: Scale development and validation", Journal of the Academy of Marketing Science, Vol. 24 No. 1, pp. 3-16.

Daily, B. and Bishop, J. (2003), TQM Workforce Factors and Employment Involvement: The Pivotal Role of Teamwork, Sage, Thousand Oaks, CA.

Dean, D., Arroyo-Gamez, R., Punjaisri, K. and Pich, C. (2016), "Internal brand co-creation: The experimental brand meaning cycle in higher education", Journal of Business Research, Vol. 69 No. 8, pp. 3041-3048. 
Devasagayam, P., Buff, C., Aurand, T. and Judson, K. (2010), "Building brand community membership within organizations; a viable internal branding alternative", Journal of Product \& Brand Management, Vol. 19 No. 3, pp. 210-217.

De Vries, N. and Carlson, J. (2014), "Examining drivers and brand performance implications of customer engagement with brands in the social media environment", Journal of Brand Management, Vol. 21 No. 6, pp. 495-515.

Dwivedi, A., Wilkie, D., Johnson, L. and Weerawardena, J. (2016), "Establishing measures and drivers of consumer brand engagement behaviour", Journal of Brand Management, Vol. 23 No. 5, pp.41-69.

de Jong, J. and Vermeulen, P. (2003), “Organizing successful new service development: a literature review", Management Decision, Vol. 41 No. 9, pp. 844-858.

Fernandes, T. and Moreira, M. (2019), "Consumer brand engagement, satisfaction and brand loyalty: a comparative study between functional and emotional brand relationships", Journal of Product \& Brand Management, Vol. 28 No. 2, pp. 274-286.

Fernandez, S. and Moldogaziev, T. (2013), "Using employee empowerment to encourage innovative behaviour in the public sector", Journal of Public Administration research and Theory, Vol. 23 No. 1, pp. 155-187.

Fornell, C. and Larcker, D.F. (1981), "Evaluating structural equation models with unobservable variables and measurement error", Journal of Marketing Research Vol. XVIII No. 1, pp. 39-50.

France, C., Merrilees, B. and Miller, D. (2015), "Customer brand co-creation: a conceptual model”, Marketing Intelligence \& Planning, Vol. 33 No. 6, pp. 848-864.

France, C., Merrilees, B. and Miller, D. (2016), “An integrated model of customer-brand engagement: Drivers and consequences", Journal of Brand Management, Vol. 23 No. 2, pp. 119-136. 
France, C., Grace, D., Merrilees, B. and Miller, D. (2018), Customer brand co-creation behaviour: conceptualization and empirical validation", Marketing Intelligence \& Planning, Vol. 36 No. 3, pp. 334-348.

Gapp, R. and Merrilees, B. (2006), "Important factors to consider when using internal branding as a management strategy: a healthcare case study", Journal of Brand Management, Vol. 14 No. 1-2, pp. 162-176.

Gill-Simmen, L., Macinnis, D., Eisingerich, A. and Park, C. (2018), "Brand-self connections and brand prominence as drivers of employee brand attachment", Academy of Marketing Science Review, Vol. 8, pp. 128-146.

Hakanen, T. and Jaakkola, E. (2012), “Co-creating customer-focused solutions within business networks: a service perspective”, Journal of Service Management, Vol. 23 No. 4, pp. 593-611.

Hair, J., Black, W., Babin, B., Anderson, R. and Tatham, R. (2006), Multivariate Data Analysis, Englewood Cliffs, NJ: Prentice Hall.

Harp, E., Scherer, L. and Allen, J. (2017), "Volunteer engagement and retention: Their relationship to community service self-efficacy", Nonprofit and Voluntary Sector Quarterly, Vol. 46 No. 2, pp. 442-458.

Henseler, J., Ringle, C. and Sarstedt, M. (2015). “A new criterion for assessing discriminant validity in variance-based structural equation modeling", Journal of the Academy of Marketing Science, Vol. 43 No. 1, pp. 115-135.

Hollebeek, L. (2011), "Demystifying customer brand engagement: Exploring the loyalty nexus", Journal of Marketing Management, Vol. 27 No. 7/8, pp. 785-807.

Iglesias, O., Ind, N. and Alfaro, M. (2013), “The organic-view of the brand: Towards a brand value cocreation model", Journal of Brand Management, Vol. 20 No. 8, pp. 670-688. 
Ind, N. (2003), "Inside out: how employees build value", Journal of Brand Management, Vol. 10 No. 6, pp. 393-402.

Ind, N. (2004), Living the Brand ( $2^{\text {nd }}$ edn), Kogan Page, London.

Ind, N., Coates, N. and Lerman, K. (2020), "The gift of co-creation: what motivates customers to participate”, Journal of Brand Management, Vol. 27 No. 2, pp. 181-194.

Ind, N., Fuller, C. and Trevail, C. (2012), Brand Together: How Co-creation Generates Innovation and Re-Energizes Brands, Kogan Page, London.

Ind, N., Iglesias, O. and Schultz, M. (2013), "Building Brands Together. Emergence and Outcomes of Co-Creation”, California Management Review, Vol. 55 No. 3, pp. 5-26. Jaakkola, E. and Alexander, M. (2014), “The role of customer engagement behavior in value co-creation: A service system perspective", Journal of Service Research, Vol. 17 No. 3, pp. 247-261.

Jeanes, E. (2013), “The construction and controlling effect of a moral brand", Scandinavian Journal of Management, Vol. 29, pp. 163-172.

Jose, G. and Mampilly, S. R. (2014), "Psychological empowerment as a predictor of employee engagement: An empirical attestation”, Global Business Review, Vol. 15 No. 1, pp. 93 104.

Lee, Y.-K., Kim, S. and Kim, S. (2014), "The impact of internal branding on employee engagement and outcome variables in the hotel industry", Asia Pacific Journal of Tourism Research, Vol. 19 No. 12, pp. 1359-1380.

Little, T.D., Cunningham, W.A., Shahar, G. and Widaman, K.F. (2002), “To parcel or not to parcel: Exploring the question, weighing the merits", Structural Equation Modeling: A Multidisciplinary Journal Vol 9 No. 2, pp. 151-173. 
Lin, W. and Van Ryzin, G. (2012), "Web and mail surveys: An experimental comparison of methods for nonprofit research", Nonprofit and Voluntary Sector Quarterly, Vol. 41 No. 6, pp. 1014-1028.

Liu, G., Chapleo, C., Ko, W. W. and Ngugi, I. K. (2015), “The role of internal branding in nonprofit brand management: An empirical investigation", Nonprofit and Voluntary Sector Quarterly, Vol. 44 No. 2, pp. 319-339.

Low, N., Butt, S., Ellis Paine, A. and Davis Smith, J. (2007), Helping Out: A National Survey of Volunteering and Charitable Giving, New Zealand Cabinet Office, Wellington.

Merrilees, B. (2016a), "Internal branding: Dissecting, re-analysing and re-directing the literature.” In Dall’Olmo Riley, F., Singh, J., and Blankson, C. (Eds.) The Routledge Companion Contemporary Brand Management. Routledge: London, Ch 22, pp. 324337.

Merrilees, B. (2016b), "Interactive brand experience pathways to customer-brand engagement and value co-creation”, Journal of Product \& Brand Management, Vol. 25 No. 5, pp. 402-408.

Merrilees, B. and Frazer, L. (2013), “Internal branding: Franchisor leadership as a critical determinant", Journal of Business Research, Vol. 66 No. 2, pp. 158-164.

Merrilees, B. and Miller, D. (2019), “Companion shopping: the influence on mall brand experiences”, Marketing Intelligence \& Planning, Vol. 37 No. 4, pp. 465-478.

Merrilees, B., Miller, D. and Yakimova, R. (2017), "The role of staff engagement in facilitating staff-led value co-creation”, Journal of Service Management, Vol. 28 No. 2, pp. 250264.

Merrilees, B., Miller, D. and Yakimova, R. (2020), "Volunteer retention motives and determinants across the volunteer lifecycle", Journal of Nonprofit \& Public Sector Marketing, Vol. 37 No. 1, pp. 25-46. 
Miller, D. and Merrilees, B. (2013), "Rebuilding community corporate brands: A total stakeholder involvement approach”, Journal of Business Research, Vol. 66 No. 2, pp. 172-179.

Minkiewicz, J., Evans, J. and Bridson, K. (2014), "How do consumers co-create their experiences? An exploration in the heritage sector", Journal of Marketing Management, Vol. 30 No. 1-2, pp. 30-59.

Morhart, F., Herzog, W. and Tomczak, T. (2009), "Brand-specific leadership: turning employees into brand champions", Journal of Marketing, Vol. 73 No. 5, pp. 122-142.

Mulder, M. R., Rapp, J. M., Hamby, A. and Weaver, T. (2015), “Consumer transformation through volunteer service experiences", The Service Industries Journal, Vol. 35 No. 15/16, pp. 865-882.

M'zunga, S., Merrilees, B. and Miller, D. (2010), "Brand management to protect brand equity: a conceptual model", Journal of Brand Management, Vol. 17 No. 8, pp. 605-617.

Napoli, J. (2006), “The impact of nonprofit brand orientation on organizational performance", Journal of Marketing Management, Vol. 22 No. 7/8, pp. 673-694.

Narissara, S., Nguyen, B., Melewar, T. C., Sujchaphong, P. and Chen, J. (2020), “A framework of brand-centred training and development activities, transformational leadership and employee brand support in higher education”, Journal of Brand Management, Vol. 27 No. 2, pp. 143-159.

Nunnally, J. and Bernstein, I. (1994), Psychometric Theory, (3 ${ }^{\text {rd }}$ ed.) McGraw-Hill, New York.

Ockenden, N. and Hutin, M. (2008), Volunteering to Lead: A Study of Leadership in Small, Volunteer-Led Groups, New Zealand Institute for Volunteering Research. 
Olaru, D., Purchase, S. and Peterson, N. (2008), "From customer value to repurchase intentions and recommendations", Journal of Business and Industrial Marketing, Vol. 23 No. 8, pp. 554-565.

Ordanini, A. and Parasuraman, A. (2011), "Service innovation viewed through a servicedominant logic lens: a conceptual framework and empirical analysis", Journal of Service Research, Vol. 14 No. 1, pp. 3-23.

Palmer, A. (1996), "Integrating brand development and relationship marketing", Journal of Retailing and Consumer Services, Vol. 3 No. 4, pp. 251-257.

Piehler, R., King, C., Burmann, C. and Xiong, L. (2016), "The importance of employee brand understanding, brand identification, and brand commitment in realizing brand citizenship behaviour", European Journal of Marketing, Vol. 50 No. 9-10, pp. 15751601.

Punjaisri, K. and Wilson, A. (2011), "Internal branding process: key mechanisms, outcomes, and moderating factors", European Journal of Marketing, Vol. 45 No. 9/10, pp. 15211537.

Punjaisri, K., Wilson, A. and Evanschitzky, H. (2009), "Internal branding to influence employee's brand promise delivery: A case study in Thailand", Journal of Service Management, Vol. 20, No. 5, pp. 561-579.

Rich, B., Lepine, J. and Crawford, E. (2010), “Job engagement: Antecedents and effects on job performance", Academy of Management Journal, Vol. 53 No. 3, pp. 617-635.

Riketta, M. (2005), “Organizational identification: A meta-analysis", Journal of Vocational Behavior, Vol. 66 No. 2, pp. 358-384.

Saleem, F.Z. and Iglesias, O. (2016), "Mapping the domain of the fragmented field of internal branding”, Journal of Product \& Brand Management, Vol. 25 No. 1, pp. 43-57. 
Schmeltz, L. and Kjeldsen, A. (2019), "Co-creating polyphony or cacophony? A case study of a public organization's brand co-creation process and the challenge of orchestrating multiple internal voices”, Journal of Brand Management, Vol. 26 No. 3, pp.304-316.

Schmidt, H. and Baumgarth, C. (2018), "Strengthening internal brand equity with brand ambassador programs. Development and testing of a success factor model”, Journal of Brand Management, Vol. 25 No. 3, pp. 250-265.

Shamim, A., Ghazali, Z. and Albinsson, P. (2016), “An integrated model of corporate brand experience and customer value co-creation behaviour", International Journal of Retail \& Distribution Management, Vol. 44 No. 2, pp. 139-158.

Shantz, A., Saksida, T. and Alfes, K. (2014), "Dedicating time to volunteering: Values, engagement, and commitment to beneficiaries", Applied Psychology, Vol. 63 No. 4, pp. 671-697.

Thelander, A. and Sawe, F. (2015), The challenge of internal stakeholder support for co-created branding strategy", Public Relations Inquiry, Vol. 4 No. 3, pp. 323-343.

Thomas, T. (2016). Improving volunteer engagement: Results of a staff needs assessment as a community-based organization. Georgia State University. Accessed on 01 November 2016, from http://scholarworks.gsu.edu/iph_capstone/15

Tossavainen, P. (2017), “Co-create with stakeholders: Action research approach in service development", Action Research, Vol. 15 No. 3, pp. 276-293.

Veloutsou, C., and Moutinho, L. (2009), "Brand relationships through brand reputation and brand tribalism", Journal of Business Research, Vol. 66 No. 2, pp. 314-322.

Wallace, E., de Chernatony, L. and Buil, I. (2013), "Building bank brands: how leadership behaviour influences employee commitment”, Journal of Business Research, Vol. 66 No. 2, pp. 165-171. 
Wieseke, J., Aherne, M., Lam, S. and van Dick, R. (2009), "The role of leaders in internal marketing”, Journal of Marketing, Vol 73 No. 2, pp.123-145.

Yi, Y. and Gong, T. (2013), “Customer value co-creation behavior: Scale development and validation”, Journal of Business Research, Vol. 66 No. 9, pp. 1279-1284.

Zeithaml, V., Bitner, M., and Gremler, D. (2009), Services Marketing: Integrating Customer Focus across the Firm, McGraw-Hill, New York, NY. 